\title{
Action Spectrum of Photoinduced Conidiation in Alternaria cichorii
}

\author{
By DEMETRIOS J. VAKALOUNAKIS $\dagger$ \\ Department of Plant Pathology, University of Wisconsin, Madison, Wisconsin, USA
}

(Received 8 April 1986; revised 14 July 1986)

\begin{abstract}
An action spectrum for photoinduced conidiophore formation in the fungus Alternaria cichorii was determined by exposing colonies to monochromatic radiation obtained from a diffraction grating monochromator. The action spectrum showed a peak near $290 \mathrm{~nm}$ with a noticeable shoulder between 310 and $330 \mathrm{~nm}$ and another one between 260 and $265 \mathrm{~nm}$. This action spectrum has many common characters with those for photoinduced conidiophore formation of Helminthosporium oryzae and Alternaria tomato, where the induction of conidiophore formation is controlled by a blue-light-inducible, near-UV-reversible, photoreaction.
\end{abstract}

\section{INTRODUCTION}

Sporulation in many fungi is induced by exposure to light. There seem to be two main categories of response: one group of light-sensitive fungi responds to wavelengths of 330$510 \mathrm{~nm}$ and the other to UV radiation of wavelengths less than $330 \mathrm{~nm}$ (Tan, 1978). Conidia are formed in colonies of Alternaria cichorii when exposed to UV radiation of wavelengths less than $340 \mathrm{~nm}$ but none are formed in colonies exposed to violet, blue-green, yellow, orange or red light (Vakalounakis, 1981). Sporulation in $A$. cichorii presents two distinct phases: an inductive phase' leading to formation of conidiophores and a 'terminal phase' leading to formation of conidia (Vakalounakis, 1981; Vakalounakis \& Christias, 1986). The inductive phase is induced by near-UV radiation of wavelengths below $340 \mathrm{~nm}$ and proceeds most efficiently at high temperatures, while the terminal phase is inhibited by blue light $(360-530 \mathrm{~nm})$ and is operative at lower temperatures. The purpose of this study was to determine an action spectrum for photoinduced conidiophore formation in $A$. cichorii and reveal the probable absorption characteristics of the photoreceptor, and also to compare this action spectrum with those for photoinduced conidiation of Helminthosporium oryzae and Alternaria tomato, in which the induction of conidiophore formation is under control of a blue-light-inducible, near-UVreversible photoreaction, regulated by the 'mycochrome' system.

\section{METHODS}

Strain and culture conditions. The isolate of $A$. cichorii used in this study has been described (Vakalounakis, 1981; Vakalounakis \& Christias, 1981). It was grown at $25 \pm 0.5^{\circ} \mathrm{C}$ on potato dextrose agar in standard $9 \mathrm{~cm}$ Petri dishes containing $15 \mathrm{ml}$ medium with an initial $\mathrm{pH}$ of 6.3 . Cultures, inoculated with agar plugs from the periphery of 5 -d-old cultures grown in darkness at $25 \pm 0.5{ }^{\circ} \mathrm{C}$, were grown for $4 \mathrm{~d}$ in darkness, exposed to monochromatic radiation and then incubated for $48 \mathrm{~h}$ in darkness before being examined microscopically. During irradiation, the lids of the Petri dishes were removed and the dishes were transferred to an optical bench where they were held vertically under illumination from a dim red light with wavelengths longer than $600 \mathrm{~nm}$.

Irradiation. Monochromatic radiation was obtained from a Bausch and Lomb $250 \mathrm{~mm}$ diffraction grating monochromator with a $900 \mathrm{~W}$ Xenon lamp (Engelhard Hanovia, Inc.). A Corning glass filter no. 0-53 was used to reduce stray light as well as to eliminate the overlapping second-order spectrum at the longer wavelengths (Table 1). Intensity of radiation was measured with a model E20 thermopile (Kipp and Zonen) and an A70 galvanometer (Kipp and Zonen). When necessary, intensity of radiation was adjusted by using suitable neutral-density filters (Vacuum Optics Corporation of Japan) at the exit slit. Cultures were irradiated from 250 to $340 \mathrm{~nm}$ at $10 \mathrm{~nm}$

† Present address: Plant Protection Institute, PO Box 1802, Heraklio, Crete, Greece. 
Table 1. Wavelengths, intensities and range of exposure times used in action spectrum study of A. cichorii

$\begin{gathered}\text { Wavelength } \\ \text { (nm) }\end{gathered}$
250
260
270
280
290
300
310
320
330
340

$\begin{gathered}\text { Intensity } \\ \left(\mathrm{mW} \mathrm{m} \mathrm{m}^{-2}\right)\end{gathered}$
803
852
881
895
509
506
366
372
1956
4118

Filter*
None
None
None
None
None
None
None
$0-53$
$0-53$
$0-53$

Duration of
irradiation $\dagger$
$a$
$b$
$b$
$b$
$b$
$b$
$a$
$a$
$c$
$d$

* Filter no. 0-53 transmits wavelengths longer than $280 \mathrm{~nm}$.

$\dagger a, 10,30,50,70,90,110$ and $130 \mathrm{~s} ; b, 10,20,30,40,50$ and $60 \mathrm{~s} ; c, 10,30,50,70,90,110,130,150$ and $170 \mathrm{~s}$; $d, 100,1000,5000,10000$ and $50000 \mathrm{~s}$.

intervals in regions of the spectrum in which preliminary studies had indicated the presence of peaks of activity. Half-band width was about $10 \mathrm{~nm}$ at all wavelengths. Intensity of radiation at each wavelength was kept constant while the duration of irradiation was varied (Table 1). This procedure is fully valid if the Bunsen-Roscoe Law (full reciprocity between intensity and duration of irradiation) can be shown to hold at the most effective wavelengths (Carlile, 1965). For this purpose two experiments were done with various time/intensity combinations at $290 \mathrm{~nm}$ and $320 \mathrm{~nm}$.

Determination of conidiation response. The number of conidia produced, which under these experimental conditions was equal to the number of conidiophores, was counted in situ in a zone that corresponded to the growing periphery at the time of irradiation (Vakalounakis \& Christias, 1981).

The standard effect selected was governed by various considerations. Vakalounakis (1981) showed that as doses at the shorter UV wavelengths were increased, so sporulation was inhibited. In addition, although radiation in the region $250-270 \mathrm{~nm}$ stimulated sporulation, the maximum density of spores formed at these wavelengths was generally lower than at the longer wavelengths. Another important practical consideration was the inability to measure the density of sporulation accurately when spores were produced very abundantly. Because of these considerations the standard effect selected was the production of 100 conidia $\mathrm{mm}^{-2}$, low enough to enable accurate counting of conidia and to minimize possible inhibitory effects; this response also occurred within the linear portion of the dose-response curves. Dose-response curves were plotted for each monochromatic radiation used. The dose that induced the standard effect was calculated for each monochromatic radiation series by the following formula: dose $\left(\mathrm{mJ} \mathrm{m}^{-2}\right)=$ intensity $\left(\mathrm{mW} \mathrm{m}^{-2}\right) \times$ duration of irradiation (s). The action spectrum was obtained by plotting the reciprocals of the standard effect dose against wavelength. Relative effectiveness was normalized at $290 \mathrm{~nm}$.

For each treatment three colonies were irradiated, and 12 counts were made for each colony. Replicate experiments gave similar results.

\section{RESULTS AND DISCUSSION}

Dose-response curves (Fig. 1) and the action spectrum for light-induced sporulation of Alternaria cichorii (Fig. 2) showed a peak near $290 \mathrm{~nm}$, with shoulders in the $315-320 \mathrm{~nm}$ and 260-265 nm regions. Reciprocity (equal response) between intensity and duration of irradiation was found to hold at 290 and $320 \mathrm{~nm}$ (Table 2). The action spectrum was obtained by plotting the reciprocals of the standard effect dose (Table 3) against wavelength. If these data were corrected for radiation in quantum energy at the different wavelengths and then plotted as reciprocals, the resultant action spectrum was still very similar to that shown in Fig. 2 . This action spectrum resembles the absorption spectra for many substances, including proteins and aromatic amino acids (Harm, 1980). Long UV radiation $(330 \mathrm{~nm})$ only slightly stimulated conidiation. The lower limit of effective radiation was around $250 \mathrm{~nm}$, but effectiveness of shorter-wavelength far-UV cannot be excluded since such irradiation was not tested in these experiments. 


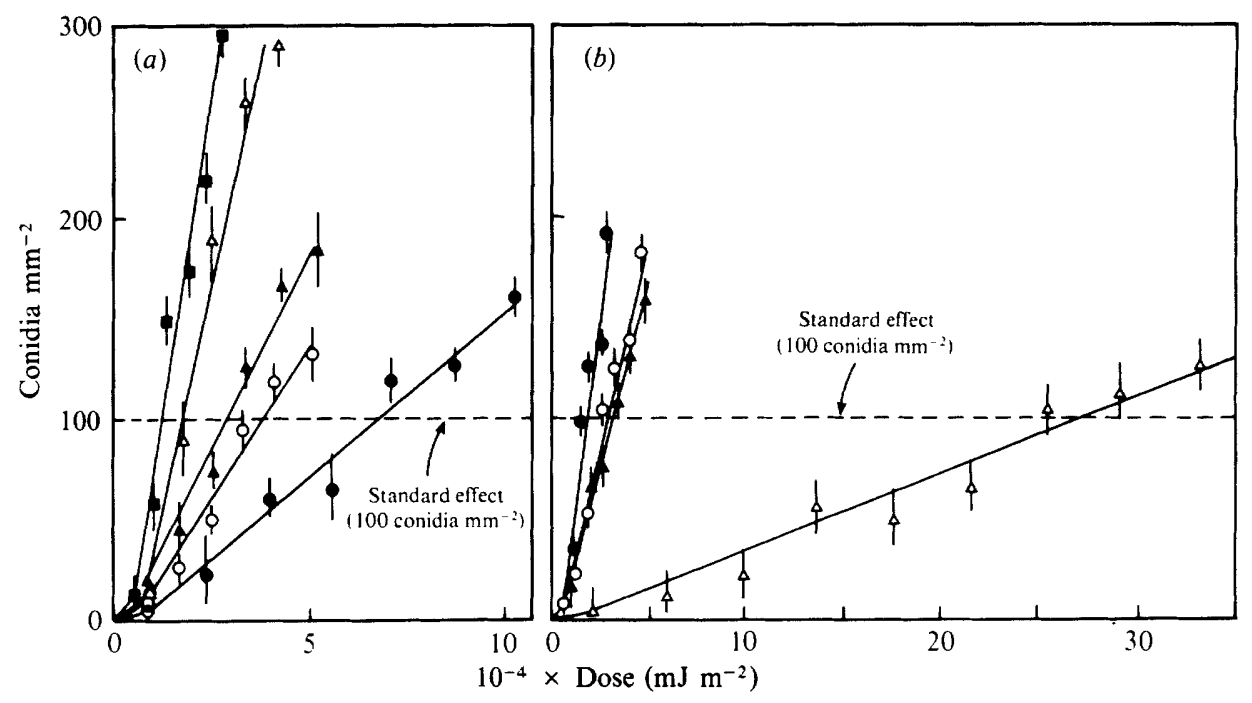

Fig. 1. Dose-response curves for induction of conidophore formation in $A$. cichorii from which standard effect doses were obtained: (a) $250 \mathrm{~nm}(O), 260 \mathrm{~nm}(O), 270 \mathrm{~nm}(\triangle), 280 \mathrm{~nm}(\triangle), 290 \mathrm{~nm}$

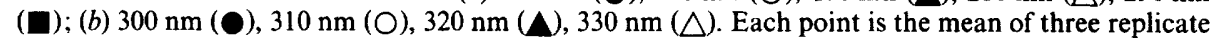
cultures with 12 counts per replicate, \pm SD (vertical bars).

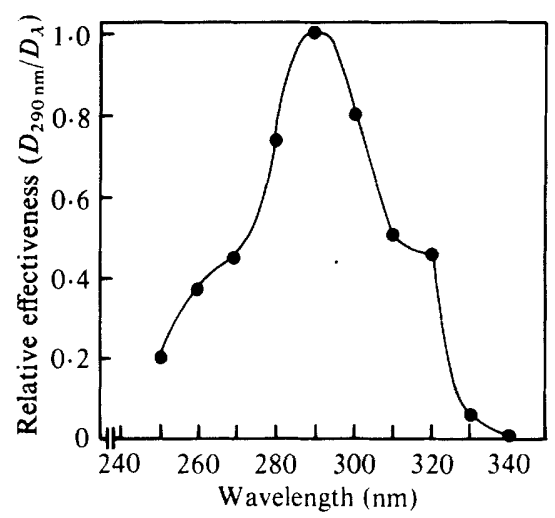

Fig. 2. Action spectrum for induction of conidiophore formation in $\boldsymbol{A}$. cichorii. Relative effectiveness was normalized at $290 \mathrm{~nm}$. $D$, dose needed to produce 100 conidia $\mathrm{mm}^{-2}$.

The action spectrum of photosporogenesis in $A$. cichorii has similarities with action spectra of conidiation reported for Ascochyta pisi (Leach \& Trione, 1965), for Pleospora herbarum, Stemphylium botryosum and Alternaria dauci (Leach \& Trione, 1966), for S. solani (Sproston, 1971), for Leptosphaerulina trifolii (Leach, 1972), for Helminthosporium oryzae (Yamamura et al., 1977) and for Botrytis cinerea (Honda \& Yunoki, 1978). In each case the response included a main peak around $280-300 \mathrm{~nm}$, a secondary peak at $260-270 \mathrm{~nm}$, minimum stimulation around $250-260 \mathrm{~nm}$ and no stimulation by wavelengths longer than $340 \mathrm{~nm}$. In this investigation additional stimulation was measured between 310 and $330 \mathrm{~nm}$ in the action spectrum of $A$. cichorii. Similar stimulation between 310 and $330 \mathrm{~nm}$ has also been detected in the action spectra for sporulation of $A$. tomato (Kumagai, 1983a), H. oryzae (Yamamura et al., 1977) and $S$. botryosum (Leach \& Trione, 1966). On the other hand, close to the stimulation between 310 and $330 \mathrm{~nm}$ was the small peak in activity at $303-310 \mathrm{~nm}$ which has been found in the action spectra of photoinduced conidiation of $B$. cinerea (Honda \& Yunoki, 1978), P. herbarum (Leach \& Trione, 1966) and L. trifolii (Leach, 1972). The increase in effectiveness at $230 \mathrm{~nm}$ observed in 
Table 2. Reciprocity of conidiation response at $290 \mathrm{~nm}$ and $320 \mathrm{~nm}$

The results are means $\pm S D$.

$\begin{array}{ccccc}\begin{array}{c}\text { Wavelength } \\ (\mathrm{nm})\end{array} & \begin{array}{c}\text { Intensity } \\ \left(\mathrm{mW} \mathrm{m}^{-2}\right)\end{array} & \begin{array}{c}\text { Duration of } \\ \text { irradiation } \\ (\mathrm{s})\end{array} & \begin{array}{c}\text { Dose } \\ \left(\mathrm{mJ} \mathrm{m}^{-2}\right)\end{array} & \begin{array}{c}\text { Conidiation } \\ (\text { conidia mm }\end{array} \\ 290 & 1350 & 10 & 13500 & 130 \pm 20 \\ & 700 & 20 & 14000 & 126 \pm 15 \\ & 350 & 40 & 14000 & 134 \pm 25 \\ & 220 & 60 & 13200 & 108 \pm 18 \\ 320 & 160 & 80 & 12800 & 115 \pm 20 \\ & 1500 & 20 & 30000 & 112 \pm 13 \\ & 750 & 40 & 30000 & 98 \pm 10 \\ & 500 & 60 & 30000 & 110 \pm 18 \\ & 400 & 80 & 32000 & 127 \pm 30 \\ & 300 & 100 & 30000 & 115 \pm 25 \\ & 250 & 120 & 30000 & 105 \pm 20\end{array}$

Table 3. Exposures at different wavelengths necessary to induce the formation of 100 conidia $\mathrm{mm}^{-2}$ (standard effect)

$\begin{array}{cccc}\begin{array}{c}\text { Wavelength } \\ (\mathrm{nm})\end{array} & \begin{array}{c}\text { Intensity } \\ \left(\mathrm{mW} \mathrm{m}^{-2}\right)\end{array} & \begin{array}{c}\text { Duration of } \\ \text { irradiation } \\ (\mathrm{s})\end{array} & \begin{array}{c}\text { Dose } \\ \left(\mathrm{mJ} \mathrm{m}^{-2}\right)\end{array} \\ 250 & 803 & 85 \cdot 0 & 68255 \\ 260 & 852 & 44 \cdot 5 & 37914 \\ 270 & 881 & 34 \cdot 4 & 30306 \\ 280 & 895 & 20.9 & 18706 \\ 290 & 509 & 26.8 & 13641 \\ 300 & 506 & 33 \cdot 7 & 17052 \\ 310 & 366 & 74 \cdot 6 & 27304 \\ 320 & 372 & 81 \cdot 5 & 30318 \\ 330 & 1956 & 139 \cdot 6 & 273058\end{array}$

the action spectra of other fungi (Leach \& Trione, 1965, 1966; Sproston, 1971; Honda \& Yunoki, 1978) cannot be excluded from the action spectrum of $\boldsymbol{A}$. cichorii since this wavelength was not tested in our experiments.

Conidial development in $A$. cichorii is controlled by a blue and near-UV reversible photoreaction regulated by the 'mycochrome' system at two developmental stages: the inductive stage of conidiophore formation (Kumagai, 1983b) and the maturation stage of conidiophore development (Vakalounakis, 1981; Vakalounakis \& Christias, 1981, 1983, 1985; Vakalounakis et al., 1983). Such a reversible photoreaction has also been found in the induction of conidiation in $A$. tomato (Kumagai, 1982) and $H$. oryzae (Kumagai, 1983a) and in the maturation of conidiophores in $\boldsymbol{A}$. tomato (Kumagai \& Oda, 1969), H. oryzae (Honda et al., 1968), B. cinerea (Tan, 1974) and $S$. botryosum (Vakalounakis, 1982). Common characters in the action spectra for photoinduced sporulation among all the above-mentioned fungi suggest that conidiophore maturation in $S$. solani may be controlled by the blue and near-UV reversible photoreaction involved in the 'mycochrome' system and also that the blue and near-UV reversible photoreaction may control the inductive stage of conidiophore formation in $B$. cinerea, $S$. botryosum and $S$. solani.

\section{REFERENCES}

Carlile, M. J. (1965). Photobiology of fungi. Annual Review of Plant Physiology 16, 175-202.

HARM, W. (1980). Biological Effects of Ultraviolet Radiation. New York: Cambridge University Press.
HoNDA, Y. \& YuNOKI, T. (1978). Action spectrum for photosporogenesis in Botrytis cinerea Pers. ex Fr. Plant Physiology 61, 711-713.

HoNDA, Y., SACAMOTO, M. \& ODA, Y. (1968). Blue and 
near ultraviolet reversible photoreaction on the sporulation of Helminthosporium oryzae. Plant and Cell Physiology 9, 603-607.

KumaGaI, T. (1982). Blue and near ultraviolet reversible photoreaction in the induction of fungal conidiation. Photochemistry and Photobiology 35, 123-125.

Kumagai, T. (1983a). Action spectra for the blue and near ultraviolet reversible photoreaction in the induction of fungal conidiation. Physiologia plantarum 57, 468-471.

Kumagal, T. (1983b). Mycochrome system and the effect of molecular oxygen in the reversible photoinduction of conidiation in the fungus Alternaria cichorii. Physiologia plantarum 59, 590-594.

KumagaI, T. \& ODA, Y. (1969). Blue and near ultraviolet reversible photoreaction in conidial development of the fungus Alternaria tomato. Development, Growth and Differentiation 11, 130-142.

LEACH, C. M. (1972). An action spectrum for lightinduced sexual reproduction in the ascomycete fungus Leptosphaerulina trifolii. Mycologia 64, 475490.

LeACH, C. M. \& Trione, E. J. (1965). An action spectrum for light-induced sporulation in the fungus Ascochyta pisi. Plant Physiology 40, 808-812.

LeACH, C. M. \& Trione, E. J. (1966). Action spectra for light-induced sporulation of the fungi Pleospora herbarum and Alternaria dauci. Photochemistry and Photobiology 5, 621-630.

SPRoston, T. (1971). An action spectrum for ultraviolet-induced sporulation in the fungus Stemphylium solani Weber. Photochemistry and Photobiology 14, 571-576.

TAN, K. K. (1974). Complete reversibility of sporulation by near-ultraviolet and blue light in Botrytis cinerea. Transactions of the British Mycological Society 63, 203-205.
TAN, K. K. (1978). Light-induced fungal development. In The Filamentous Fungi, vol. 3, pp. 334-357. Edited by J. E. Smith \& D. R. Berry. London: Edward Arnold.

VAKALOUNAKIS, D. J. (1981). Effects of ultraviolet and visible light and of temperature on the sporulation of the fungus Alternaria cichorii Nattrass. PhD thesis, Athens College of Agricultural Sciences, Greece.

VAKalounakis, D. J. (1982). Photosporogenesis in the fungus Stempylium botryosum with particular reference to a blue and near ultraviolet reversible photoreaction which controls its conidiation. Agricultural Research 6, 143-152.

VaKalounakis, D. J. \& Christias, C. (1981). Sporulation in Alternaria cichorii is controlled by a blue and near ultraviolet reversible photoreaction. Canadian Journal of Botany 59, 626-628.

Vakalounakis, D. J. \& Christias, C. (1983). Mycochrome system and conidiogenesis in Alternaria cichorii. Phytopathology 73, 798 (abstract).

Vakalounakis, D. J. \& Christias, C. (1985). Bluelight inhibition of conidiation in Alternaria cichorii. Transactions of the British Mycological Society 85, 285-289.

Vakalounakis, D. J. \& Christias, C. (1986). Light quality, temperature and sporogenesis in Alternaria cichorii. Transactions of the British Mycological Society 86, 247-254.

Vakalounakis, D. J., Christias, C. \& Malathrakis, N. E. (1983). Interaction of light quality and temperature on the vegetative reversion of conidiophores in Alternaria cichorii. Canadian Journal of Botany 61, 626-630.

Yamamura, S., Kumagai, T. \& Oda, Y. (1977). An action spectrum for photoinduced conidiation in Helminthosporium oryzae. Plant and Cell Physiology 18, 1163-1166. 